\title{
LA TRATA DE SERES HUMANOS EN LA LEGISLACIÓN NACIONAL E INTERNACIONAL Y SU RELACIÓN CON LA PROTECCIÓN INTERNACIONAL
}

\author{
Borja Fernández Burgueño \\ Universidad Nacional Autónoma de Madrid / UNED \\ Comisión Española de Ayuda al Refugiado (CEAR)
}

http://dx.doi.org/10.5209/NOMA.55490

Resumen: Este artículo pretende centrar la discusión jurídica sobre la naturaleza de la trata de seres humanos desde tres perspectivas. En la primera sección se estudiará la trata de seres humanos desde un enfoque internacional. En la segunda sección se abordará desde una óptica nacional. En la tercera sección se estudiará, desde una perspectiva nacional e internacional, la relación de la trata de seres humanos con la protección internacional. Finalmente, se concluirá con algunas propuestas para seguir progresando en la lucha contra la trata sin perder de vista la protección de las víctimas.

Palabras clave: trata de seres humanos, tráfico de seres humanos, protección internacional, delito de trata

\begin{abstract}
This article aims to focus the legal discussion on the nature of human trafficking under the light of three perspectives. In the first section, this paper will study human trafficking through an international approach. In the second section, human trafficking will be analysed from a domestic point of view. The third section examines, through both a domestic and international perspective, the relation between human trafficking and international protection. Finally, this article will conclude by underlying some recommendations to continue moving forward on the fight against human trafficking without losing track of the protection of the victims.
\end{abstract}

Keywords: human trafficking, human smuggling, international protection, crime of human trafficking

\section{Introducción}

El informe de la Comisión Europea de mayo de 2016 sobre el avance de la lucha contra la trata de seres humanos cifra en 15.846 las 'víctimas registradas' (tanto identificadas como presumidas) en la UE. La magnitud de esta cifra apunta a que la trata de seres humanos constituye un problema actual de enormes dimensiones. La OIT estima que las ganancias económicas anuales procedentes de la trata de seres humanos son de 27.800 millones de dólares de los cuales (OIT, 2014:7), cerca de la mitad, 13.300 millones de dólares, se obtienen de países industrializados (OIT, 2014:11). Los altos beneficios que generan evidencian una realidad ineludible: la sociedad está dispuesta a pagar por los productos y servicios que se obtienen de estas prácticas. 
Teniendo en consideración los anteriores datos, resulta evidente que, hasta que no se entienda que el flujo de capital que llega a las manos de los explotadores se debe de concebir desde un enfoque social poliédrico, no se podrá alcanzar una solución duradera. A pesar de las limitaciones de la actividad legislativa para corregir un problema cuyas raíces corrompen un modelo económico, social y político basado en una visión mercantilista de la inmigración, el derecho puede contribuir a remodelar la sociedad y corregir sus carencias morales.

En este sentido, este artículo pretende centrar la discusión jurídica sobre la naturaleza de la trata de seres humanos desde tres perspectivas: el derecho internacional, el derecho nacional y la protección internacional.

En la primera sección se estudiará la trata de seres humanos desde un enfoque internacional, centrándonos en el marco jurídico del Consejo de Europa y de la Unión Europea. En la segunda sección se abordará la trata desde una óptica nacional y, en concreto, a través de la evolución de la tipificación penal del delito de la trata de seres humanos, especialmente desde la entrada en vigor de la Ley Orgánica. $5 / 2010$, de 22 de junio, por la que se configura el delito de trata como un tipo penal autónomo. En la tercera sección se estudiará, desde una perspectiva nacional e internacional, la relación de la trata de seres humanos con la protección internacional. La trata de seres humanos, por definición, conlleva un desplazamiento forzado, ya sea mediante engaño, imposición o coacción, de una persona de un lugar a otro. En muchas ocasiones, la víctima tiene un temor fundado a que, si regresase a su país de origen, correría el riesgo de volver a caer en las manos de la red de traficantes o sufriría otro tipo de persecución por motivo de su identidad de género, orientación sexual o por su pertenencia a un grupo social determinado. Sin embargo, la respuesta jurídica a la trata de seres humanos ha tendido a desvincular estas víctimas de la protección internacional. Finalmente, se concluirá con algunas propuestas para seguir progresando en la lucha contra la trata sin perder de vista la protección de las víctimas.

\section{La trata de seres humanos en la legislación internacional}

Desde una perspectiva universal, podemos situar el inicio del enfoque actual de la lucha contra la trata en el Protocolo de las Naciones Unidas para Prevenir, Reprimir y Sancionar la Trata de Personas, Especialmente Mujeres y Niños (Protocolo de Palermo, 2000) por el que se pretende tanto prevenir y combatir la trata de persona como proteger y ayudar a las víctimas.

En el marco del Consejo de Europa (CdE), resulta especialmente relevante el Convenio del CdE Contra la trata de Seres Humanos de 2005 y sus mecanismos de supervisión. El GRETA es, junto con el Comité 
de las Partes, uno de los mecanismos de supervisión del Convenio Contra la Trata y su labor de vigilancia y evaluación constituye uno de los pilares de la lucha contra la trata en Europa. Hasta 2010, se podían diferenciar dos corrientes diferentes en la lucha contra la trata en el CdE. Por un lado, nos encontrábamos la actividad de los mecanismos de supervisión del Convenio del CdE Contra la trata de Seres Humanos de 2005 y, de forma paralela, del otro, el alcance del Convenio Europeo de Derechos Humanos (CEDH) a través de las sentencias del Tribunal Europeo de Derechos Humanos (TEDH). En 2010, gracias al caso Rantsev c. Chipre y Rusial, ambos mecanismos de protección de los derechos humanos confluyeron. En un comentario anterior a la sentencia White y Ovey (2010: 208) ya especularon con que el TEDH iba a ampliar el alcance del artículo 4 del CEDH sentado en Siliadin ${ }^{2}$ para interpretar el CEDH a la luz del Convenio del CdE Contra la trata de Seres Humanos de 2005 haciendo una mención específica a la trata. Este pronóstico se materializó en 2010, el mismo año de la publicación de su manual sobre el CEDH. En Rantsev el TEDH definió la trata "según el artículo 3 a) del Protocolo de Palermo y el artículo 4 a) del Convenio contra la trata de seres humanos"3. Al recurrir al Protocolo de Palermo de $2000^{4}$ y al Convenio del CdE Contra la Trata de Seres Humanos de $2005^{5}$ para definir el concepto de tratab, el TEDH consiguió canalizar el alcance de sus disposiciones, dotando de forma indirecta al contenido de estos dos instrumentos de un control jurisdiccional del que carecían. Mediante esta técnica de interpretación holística, el TEDH está consiguiendo cohesionar y armonizar los diferentes instrumentos de derechos humanos, dando forma al sistema regional de protección de derechos humanos más avanzado del mundo.

En el ámbito de la UE, hay que destacar la Decisión Marco 2002/629/JAl del Consejo, de 19 de julio de 2002, por la que se adopta un enfoque común a la lucha contra la trata de seres humanos, que es sustituida por la Directiva $2011 / 36 /$ UE relativa a la prevención y lucha contra la trata de seres humanos y a la protección de las víctimas. Si bien la Directiva $2011 / 36 /$ UE constituye un gran avance, algunos académicos han criticado ciertos aspectos de la misma. En este sentido, sumándome a la

\footnotetext{
1 Rantsev c. Chipre y Rusia, no. 25965/04. [TEDH, Sección I], 7 de enero de 2010

2 Siliadin c. Francia, no. 73316/01. [TEDH, Sección II], 26 de julio de 2005.

3 Rantsev c. Chipre y Rusia, no. 25965/04. [TEDH, Sección I], 7 de enero de 2010. Párr. 282 (traducción al español por el COE/ECHR)

4 Protocolo de las Naciones Unidas para Prevenir, Reprimir y Sancionar la Trata de Personas, especialmente Mujeres y Niños de 2000 (entrada en vigor el 25 de diciembre de 2003)

5 Convenio del Consejo de Europa de Lucha contra la Trata de 3 de mayo de 2005 (entrada en vigor: el 1 de febrero de 2008) para España entró en vigor el 1 de agosto de 2009

6 Rantsev c. Chipre y Rusia, no. 25965/04. [TEDH, Sección I], 7 de enero de 2010. Párr. 282; ver también: L.E. c. Grecia, no. 71545/12. [TEDH, Sección I], 21 de enero de 2016. Párr. 66
} 
opción de Gromek-Broc (2011: 236) resulta criticable que la directiva no haya abordado con suficiente profundidad los derechos de ciertos colectivos vulnerables como las personas discapacitadas o las mujeres embarazadas y que, a pesar de haberse anunciado como tal, no adopte un enfoque de género dirigido a cubrir las necesidades específicas de las mujeres y niñas a pesar de ser las víctimas más frecuentes de la trata de seres humanos. Por su parte, Santana Vega (2011: 225) critica que las penas previstas para el delito de trata sean inferiores a las del delito de tráfico ilegal de migrantes. Según su opinión, esto responde a un auténtico cinismo punitivo (...) que pone de manifiesto la mayor preocupación de la Unión Europea por el control de sus fronteras y de los flujos migratorios que se dirigen a su territorio, que por la dignidad del ser humano objeto de la trata" (Santana Vega, 2011: 225).

\section{La trata de seres humanos en la legislación nacional}

En esta sección se analiza el delito de trata de seres humanos en la legislación nacional, centrándonos en: la tipificación del delito con anterioridad a la L.O. 5/2010 de 22 de junio, la inclusión del art. 177bis en el C.P., la extensión de la del art. 177bis, la relación concursal con otros delitos, la naturaleza del delito y sus finalidades.

\section{La trata de seres humanos con anterioridad a la L.O. 5/2010, de 22 de junio}

En comentarios anteriores a la introducción del artículo 177bis en el Código Penal, la opinión doctrinal mayoritaria apuntaba a un uso irracional del derecho penal en materia de extranjería. Daunis Rodríguez (2010: 35) consideraba que el hecho de que la trata y el tráfico de seres humanos se regulasen en el mismo tipo penal constituía un "tratamiento legislativo inaceptable" que intentaba regular la política migratoria del Estado a través del derecho penal. En el mismo sentido se manifestaba Martínez Escamilla, quien calificaba esta utilización de la política criminal como una "insoportable banalización de la pena de prisión" (Martínez Escamilla, 2008: 20) que lesiona los derechos fundamentales y humanos de los migrantes y menoscaba el Estado de Derecho (Martínez Escamilla, 2009). Miró Llinares (2008), por su parte, también apoyaba la misma tesis, alegando que las causas del fenómeno de la migración son demasiado graves y complejas como para que se intentasen atajar por vía del Derecho penal, sosteniendo que la política criminal debería constituir el instrumento último para la protección de los bienes jurídicos más importantes, no para reducir los flujos migratorios. 


\section{La inclusión del art. 177bis en el Código Penal}

Con la entrada en vigor de la Ley Orgánica. 5/2010, de 22 de junio, se introduce el Título VII bis del Libro II del Código Penal que recoge, en su artículo único 177bis, la trata de seres humanos como un tipo penal autónomo. La mayor parte de la doctrina acogió con satisfacción la reforma. Así, Ropero Carrasco y Ruiloba Alvariño (2012: 16) señalaron que el hecho de que se separasen los delitos de trata de seres humanos y los relacionados con la inmigración clandestina, siguiendo las directrices internacionales, radicaba en una mejora considerable de la situación. De la misma manera, Daunis Rodríguez (2010: 35) consideró que la reforma fue "acertada y correcta". Sin embargo, no toda la doctrina fue igual de entusiasta al respecto. García Sedano (2013), asumiendo una postura crítica frente a la reforma del Código Penal, señaló varios matices negativos de la redacción del delito de trata, estando en desacuerdo con los siguientes aspectos del artículo: el ámbito territorial de la regulación, la distinción entre que la víctima sea nacional o extranjera, la tipificación de las distintas etapas a través de las cuales se desarrolla la conducta de trata de personas, la no inclusión de la negligencia grave como medio comisivo y la extensión de la pena.

A pesar de haber separado el delito de inmigración ilegal del de trata de seres humanos, Villacampa Estiarte (2014) advierte que ambos conceptos se confunden a menudo normativa y operacionalmente. Asimismo, esta académica señala que no se ha conseguido desvincular la protección de las víctimas de trata de la normativa de extranjería, dejando a las víctimas de la trata interna desprotegidas, y aboga por que "los esfuerzos por articular mecanismos de detección e identificación de las víctimas de trata deberían dejar de pergeñarse únicamente para extranjeros en situación irregular" (Villacampa Estiarte, 2014: 27).

\section{La pena del delito de trata}

Centrándonos en la extensión de la pena, Daunis Rodríguez (2010:37) entendió que la "penalización dispuesta no plantea problemática alguna". Por el contrario, García Sedano (2013) consideró que el legislador había incurrido en un "auténtico cinismo punitivo" por los siguientes dos motivos: el límite máximo de la pena al aplicar los tipos agravados supera los límites de la Decisión Marco 2002/629/JAI y de la Directiva $2011 / 36$ y la extensión de la pena no respeta el principio de proporcionalidad con el resto del articulado del Código Penal. Siguiendo similar línea argumental, Villacampa Estiarte (2012: 28-29) advierte que el tipo agravado del delito de trata por pertenencia a organización o grupo criminal establece un umbral punitivo "que excede de los requerimientos derivados de instrumentos internacionales 
que nos vinculan" y "conduciría a una reacción penal desproporcionadamente grave, atendiendo a los marcos punitivos aplicables a los delitos (...) correspondientes a la última fase del mismo y que consisten en la explotación-esclavización propiamente dicha de la víctima."

\section{La relación concursal de la trata de seres humanos con otros delitos}

Este último escenario al que Villacampa Estiarte (2012) se refiere en el que la pena del delito de trata superase a la pena del delito en el que consista la explotación final sería posible ya que, como dispone el apartado 9 del artículo 177 bis CP, "[e]n todo caso, las penas previstas en este artículo se impondrán sin perjuicio de las que correspondan, en su caso, por el delito del artículo 318 bis de este Código y demás delitos efectivamente cometidos, incluidos los constitutivos de la correspondiente explotación". A pesar del tenor literal de dicho apartado, no se aplica en todo caso un concurso real, sino que dependerá de las circunstancias específicas de cada caso. De esta forma, el delito de trata suele estar relacionado con el de inmigración ilegal en concurso ideal ${ }^{7}$ o real8; con el de prostitución de menores y prostitución coactiva en concurso medial ${ }^{9}$ y este, a su vez, en concurso de leyes, por principio de consunción, con el delito de coacciones ${ }^{10}$. Asimismo, la Sala Segunda del TS reunida en Pleno no Jurisdiccional acordó que "[e]l delito de trata de seres humanos (...) obliga a sancionar tantos delitos como víctimas, con arreglo a las normas que regulan el concurso real"11. La STS 2776/2016 confirma dicho acuerdo, rechazando aplicar un concurso ideal pluriofensivo en continuidad delictiva con varias víctimas ${ }^{12}$. Este criterio concursal encuentra su justificación en que, como señalan García García-Cervigón y Rodríguez Núñez (2015: 188), el bien jurídico protegido es de naturaleza personalísima y, por tanto, "se cometerán tantos delitos como víctimas hayan sido tratadas aun cuando todas ellas lo hayan sido de manera conjunta".

\footnotetext{
7 Ver ATS de 8 de mayo de 2014 en el recurso número: 10167/2014 (roj: 4801/2014)..

8 Ver: STS de 17 de junio de 2016 n de resolución 1553/2016 (roj: 2776/2016)

9 Ver SSTS de 5 de abril (roj. STS 1553/2016) de 9 de abril (roj: STS 1502/2015); de 17 de junio (roj: STS 2776/2016); de 25 de mayo (roj: STS 2345/2016); de 4 de febrero (roj: STS 53/2014), de 9 de abril (roj: 191/2015); de 8 de abril (STS 1552/2016); de 3 de marzo (roj STS 1275/2016), de 23 de diciembre (roj: 5807/2015) y auto de 6 de septiembre (roj: ATS 6495/2016)

10 Ver SSTS 463/2006, de 27 de abril y 3943/2013 de 15 de julio

11 Acuerdo del Pleno No Jurisdiccional de la Sala Segunda del Tribunal Supremo de 31 de mayo de dos mil dieciséis

12 Ver: STS de 17 de junio de 2016 (roj: 2776/2016)
} 


\section{La naturaleza del delito de trata y sus finalidades}

El delito de trata se configura como un delito doloso tendencial de consumación anticipada (García García-Cervigón y Rodríguez Núñez, 2015: 187; Martos Núñez, 2012). Por tanto, no se requiere que el resultado de la explotación se materialice, sino que basta con la creación del peligro jurídicamente desaprobado de que los fines se perpetren. Los fines a los que se refiere el artículo 177bis, en su redacción actual tras la reforma de la Ley Orgánica 1/2015 de 30 de marzo, son los siguientes: a) La imposición de trabajo o de servicios forzados, la esclavitud 0 prácticas similares a la esclavitud, a la servidumbre o a la mendicidad; b) La explotación sexual, incluyendo la pornografía; c) La explotación para realizar actividades delictivas; d) La extracción de sus órganos corporales; y e) La celebración de matrimonios forzados. Pomares (2011: 3-4) señala al respecto que "la necesaria vinculación del delito del 177 bis a determinados objetivos explotadores convierte a la trata de seres humanos en 'la versión moderna' de la trata de esclavos que se produjo hasta el siglo XIX".

Si bien se tiende a limitar el concepto de trata a aquella que persigue el fin de la explotación sexual (b.), no hay que caer en el error de obviar los fines que se enumeran en los apartados a), c), d) y e). A continuación, se destacan algunos aspectos importantes sobre estas finalidades. Giménez-Salinas Framis, Susaj y Requena Espada (2009: 22) tras analizar la dimensión laboral de la trata de personas en España (fin a.), pusieron en evidencia las dimensiones del problema de la trata por motivos laborales en España. En concreto, destacan que "el servicio doméstico es un sector vulnerable a abusos o situaciones de explotación por la propia naturaleza del trabajo, por el desconocimiento existente sobre la regulación del mismo y por la dificultad que supone controlar dicha actividad." En cuanto al fin c.), relativo a la explotación para realizar actividades delictivas, cabe destacar la dificultad de identificar a la persona como víctima de trata y no como delincuente. Problema que se incrementa cuando "en muchos casos a la persona no le gusta que la tilden de víctima, y no se reconoce bajo dicha denominación" (FEl, 2013:8). Sobre la finalidad d), relativa a la extracción de órganos, Muñoz Conde (2010: 134) señala que, si la conducta típica del 156 bis del Código Penal --consistente en promover, favorecer, facilitar o publicitar la obtención o el tráfico ilegal de órganos humanos ajenos o el trasplante de los mismos- se realiza a través de la conducta del 177bis no habrá concurso de leyes sino un concurso ideal de delitos. Finalmente, en cuanto al fin e) sobre la celebración de matrimonios forzados, resulta pertinente destacar que en relación con el delito de Matrimonio Forzado del Artículo 172 bis (a pesar de haber sido introducido por la misma Ley Orgánica 1/2015 de 30 de marzo) es posible encontrarnos con un concurso de leyes, por 
principio de consunción, entre ambas figuras al estar las coacciones generalmente abarcadas por el desvalor de la conducta del 177bis.

\section{La trata como motivo de protección internacional}

En esta sección se estudia la relación entre la trata y la protección internacional desde el punto de vista del derecho internacional de los refugiados y del derecho nacional de asilo.

\section{La trata y el derecho internacional de los refugiados}

García Cuesta (2012), poniendo de relieve que la trata de seres humanos afecta principalmente a género femenino, señala que "la trata de persona para la explotación sexual está ya siendo formalmente reconocida como una forma de violencia de género". En este sentido, Mayordomo Rodrigo (2007: 295) señala que las mujeres víctimas de trata podrían solicitar el estatuto de refugiadas bajo la Convención de Ginebra de 1951 sobre el Estatuto de los Refugiados atendiendo a la interpretación moderna del Derecho Internacional de los refugiados y, en concreto, del concepto de persecución por "pertenencia a determinado grupo social" del artículo lA de la Convención. El progreso de incorporación de las mujeres y, en concreto, de las víctimas de trata al ámbito del derecho internacional de los refugiados comenzó con la Conclusión n.39 del Comité Ejecutivo del ACNUR de 1985, fue ganando peso con las Conclusiones n.54 de 1988, n. 60 de 1989, n.64 de 1990, n. 65 de 1991, n. 68 de 1992 y n.73 de 1993 y, finalmente, se materializó en su forma actual en 2002 con las Directrices del ACNUR sobre la persecución por motivos de género ${ }^{13}$, en las cuales la trata de personas para la prostitución o explotación sexual forzosa se sanciona de forma expresa como una forma de persecución bajo la Convención de Ginebra.

\section{La relación de la trata y la protección internacional bajo el CEDH}

La jurisprudencia del Tribunal de Estrasburgo en los casos L.R. C. Reino Unido ${ }^{14}$, O.G.O C. Reino Unido ${ }^{15}$ y D.H. C. Finlandia ${ }^{16}$ confirma que la aplicación extraterritorial de la prohibición de la trata está íntimamente ligada a la protección internacional que ofrece el asilo y la protección

13 ACNUR. DIRECTRICES SOBRE PROTECCIÓN INTERNACIONAL: La persecución por motivos de género en el contexto del Artículo 1A(2) de la Convención de 1951 sobre el Estatuto de los Refugiados, y/o su Protocolo de 1967. HCR/GIP/02/01 7 de mayo de 2002. Párr. 18 http://www.acnur.org/t3/fileadmin/Documentos/BDL/2002/1753.pdf ${ }^{14}$ L.R. c. Reino Unido (decisión), no. 49113/09. [TEDH, Sección IV], 14 de junio de 2011 15 O.G.O c. Reino Unido (decisión), no. 13950/12. [TEDH, Sección IV], 18 de febrero de 2014

16 D.H. C. Finlandia, no. 30815/09. [TEDH, Sección IV], 28 de junio de 2011 
subsidiaria, archivando los casos cuando les fueron concedidos sendos estatutos de refugiado (casos L.R y O.G.O) y de protección subsidiaria (caso D.H.). No obstante, en una decisión, bajo mi punto de vista, desacertada, el TEDH archivó el asunto Idemugia c. Francia ${ }^{17}$ en el que Francia expulsa a Nigeria a una solicitante de asilo víctima de trata.

\section{La relación de la trata y la protección internacional en España}

En España, a pesar de que la ley 12/2009, de 30 de octubre, Reguladora del Derecho de Asilo y de la Protección Subsidiaria incorpore el "motivo de género" de forma explícita en la definición de refugiado (art. 3) y de haber incluido a las víctimas de trata como colectivo de especial vulnerabilidad (art. 46), la práctica y la jurisprudencia al respecto no resulta uniforme.

En ocasiones, el TS no ha sabido distinguir correctamente el asilo de la protección subsidiaria, considerando que el temor a caer en manos de la trata "no es incardinable en ninguno de los motivos previstos por la Convención de Ginebra de 1951"18. Asimismo, la actuación del Abogado del Estado también ha sido, en ocasiones, criticable, llegando a recurrir en casación posiciones incongruentes con tal eliminar todo vínculo entre la ley de asilo y la trata, incluso a la hora de conceder autorización por razones humanitarias (art. 46.3 de la Ley 12/2009 en relación con el art. 125 del Real 557/2011, de 20 de abrill19. No obstante, en el último trimestre de 2016, las autoridades españolas "han comenzado a reconocer (...) la protección internacional a mujeres que habían sido víctimas de trata con fines de explotación sexual" (CEAR, 2017). El hecho de que España camine hacia una interpretación menos restrictiva del alcance del estatuto de asilo para las víctimas de trata constituye un avance positivo. No obstante, aún queda mucho camino por recorrer hasta que la concesión del estatuto de refugiadas a las víctimas de trata que temen ser devueltas a su país de origen deje de ser una notica, sino una práctica habitual.

Por último, hay que señalar que, como bien apunta García GarcíaCervigón y Rodríguez Núñez (2015), el hecho de que aún no se haya aprobado el reglamento de la Ley de Asilo 12/2009 constituye un grave problema a la hora de aplicar las disposiciones que requieren desarrollo reglamentario, como, por ejemplo, el contenido concreto del "trato diferenciado" que habría que otorgarse a las víctimas de trata de acuerdo con el art. 46 de la Ley de Asilo.

\footnotetext{
17 Idemugia c. Francia (decisión), no. 4125/11. [TEDH, Sección V], 27 de marzo de 2012

18 STS de 21 de julio de 2015, número de recurso: 3898/2014 (roj: STS 3651/2015). FJ $2^{\circ}$

19 STS 1972/2016 de 26 de julio de 2016 (roj: 3821/2016)
} 


\section{Conclusión}

En este trabajo se ha puesto de relieve que los instrumentos nacionales e internacionales en vigor pueden llegar a ofrecer un marco multinivel efectivo en la lucha y protección frente a la trata de seres humanos. No obstante, este escenario legal es de reciente implantación, comparado con la trayectoria histórica de las distintas modalidades de esclavitud, en la que la trata de seres humanos se considera la forma de esclavitud moderna con mayor alcance, por lo que será necesario esperar a que se materialicen los efectos reales de esta nueva configuración legal de la lucha contra la trata.

En el ámbito internacional, se ha destacado la evolución jurisprudencial del CEDH sentada en el caso Rantsev, en el cual el TEDH definió la trata de acuerdo con el Protocolo de Palermo de 2000 y el Convenio del CdE Contra la Trata de Seres Humanos de 2005, consolidando un marco homógéneo de protección en el ámbito de los Estados miembros del Consejo de Europa. Asimismo, también se han subrayado los avances en el seno de la UE con la aprobación de la Directiva 2011/36/UE. No obstante, se ha lamentado que la directiva no adoptase un enfoque sensible a colectivos vulnerables como las personas discapacitadas, las mujeres embarazadas o las niñas.

En el marco nacional, con la entrada en vigor de la Ley Orgánica. $5 / 2010$, de 22 de junio, por la que se introduce el 177bis, se ha mejorado el tratamiento legal de los delitos de trata de seres humanos y los relacionados con la inmigración clandestina al tipificar la trata de seres humanos como un tipo penal autónomo. No obstante, se han identificado ciertas críticas doctrinales a la configuración del delito, considerando algunos autores que se ha incurrido en un cinismo punitivo.

Finalmente, en el tercer apartado, se ha señalado la necesidad de incluir a las víctimas de trata que temen volver a caer en manos de los explotadores o sufrir otros tipos de persecución en sus países de origen dentro del ámbito de protección del asilo. En este sentido, se han señalado las dificultades con las que las víctimas de trata se encuentran en España a la hora de solicitar asilo. No obstante, se ha destacado una evolución en la jurisprudencia y práctica española favorable hacia la inclusión de las víctimas de trata en el marco de la protección internacional.

Para concluir, conviene señalar los principios de actuación que han de ilustrar las políticas futuras de lucha contra la trata. Cordero Ramos (2012: 8) sintetiza perfectamente las líneas de actuación en los siguientes cinco verbos: (1) visibilizar, (2) prevenir, (3) garantizar el cuidado), (4) dignificar y (5) empoderar. No obstante, esta actividad solo se podrá erradicar el día que se adopte un enfoque no solo jurídico o político sino también económico ya que en la sociedad prima la 
"instrumentalización mercantilista de las personas" (Pomares Cintas, 2011 :3-4). En este sentido, García Vázquez (2010) señala acertadamente que "es preciso que la trata de seres humanos deje de ser una actividad de bajo riesgo y alta rentabilidad para la delincuencia organizada, y se transforme en una ocupación de alto riesgo y escasa rentabilidad".

\section{Referencias bibliográficas}

ACNUR (mayo de 2002). Directrices sobre Protección Internacional: La persecución por motivos de género en el contexto del Artículo lA(2) de la Convención de 1951 sobre el Estatuto de los Refugiados, y/o su Protocolo de 1967. HCR/GIP/02/01. Disponible online en: http://www.acnur.org/t3/fileadmin/Documentos/BDL/2002/1753.pdf

BONELLI JÁUDENES, E. / ULLOA JIMÉNEZ, M. (2001): Tráfico e inmigración de mujeres en España. Colombianas y ecuatorianas en los servicios domésticos y sexuales, ACSUR: Las Segovias. Disponible online en: http://www.acnur.org/fileadmin/Documentos/Publicaciones/2006/3630. pdf? view=1

COMISION ESPAÑOLA DE AYUDA AL REFUGIADO - CEAR (2017): España empieza a reconocer el derecho de asilo a las víctimas de trata. 16 enero, 2017. Disponible online en : https://www.cear.es/espanaempieza-a-reconocer-el-derecho-de-asilo-a-las-victimas-de-trata/

COMMISSION TO THE EUROPEAN PARLIAMENT AND THE COUNCIL (2016). Report on the progress made in the fight against trafficking in human beings (2016). Brussels, 19.5.2016 $\operatorname{COM}(2016)$ 267. Online en: http://ec.europa.eu/dgs/home-affairs/what-we-do/policies/organizedcrime-and-human-trafficking/trafficking-in-human-

beings/docs/commission_report_on_the_progress_made_in_the_fight_ag ainst_trafficking_in_human_beings_2016_en.pdf

CORDERO RAMOS, N. (2012). Niñas víctimas de trata. Desde los derechos humano a la ética del cuidado, Revista de Estudios Jurídicos UNESP, Vol. 16, N. 24, Disponible online en:

http://seer.franca.unesp.br/index.php/estudosjuridicosunesp/article/vie w/770

DAUNIS RODRÍGUEZ, A.- (2010): Sobre la urgente necesidad de una tipificación autónoma e independiente de la trata de personas, Indret, núm. 1. Disponible online en:

http://www.raco.cat/index.php/InDret/article/view/225334

FEI - MINISTERE DES AFFAIRES ETRANGERES (junio de 2013). Herramienta práctica para detección de víctimas de trata con fines de mendicidad forzada y explotación de actividades ilícitas. Proyecto financiado por el Prevention of and Fight against Crime Programme of the European 
Union, European Commission-Directorate-General Home Affairs. Disponible online en:

http://www.violenciagenero.msssi.gob.es/otrasFormas/trata/detectarla/ pdf/HerramientaDeteccionTSHactividadesllicitas.pdf

GARCÍA CUESTA, S. (2012): La trata en España: una interpretación de los Derechos Humanos en perspectiva de género, Dilemata, 10. Disponible online en:

http://www.dilemata.net/revista/index.php/dilemata/article/view/170/2 14

GARCÍA GARCÍA-CERVIGÓN, J. Y RODRÍGUEZ NúÑEZ, A. (2015) Política Criminal y Derechos Humanos. Editorial Universitaria Ramón Areces: Madrid

GARCÍA SEDANO, T. (junio 2013): La reforma del código penah español motivada por la trasposición de la directiva 2011/36, sobre prevención y lucha contra la trata de seres humanos y protección de las víctimas, REJIE: Revista Jurídica de Investigación e Innovación Educativa, n 8 Disponible online en: http://www.eumed.net/rev/rejie/08/codigopenal.html

GARCÍA VÁZQUEZ, S (2010): Inmigración ilegal y trata de personas en la Unión Europea: la desprotección de la víctima, REDCE10, Disponible online en:

http://www.ugr.es/ redce/REDCE10/articulos/06SoniaGarciaVazquez.ht $\mathrm{m}$

GIMÉNEZ-SALINAS FRAMIS, A. / SUSAJ, G. / Laura REQUENA ESPADA, L. (2009). Dimensión laboral de la trata de personas en España, Revista Electrónica de Ciencia Penal y Criminología - RECPC 11-04. Disponible online en: http://www.eumed.net/rev/rejie/08/codigo-penal.pdf

GROMEK-BROC, K. (2011): EU Directive on preventing and combating trafficking in human beings and protecting victims: will it be effective?, Nova et Vétera, Vol. 20, $N^{\circ}$. 64. Disponible online en: https://dialnet.unirioja.es/descarga/articulo/3897658.pdf

INTERNATIONAL LABOUR OFFICE - ILO. (2014). Profits and Poverty: The Economics of Forced Labour. ILO publications : Geneva. Disponible online en: http://www.ilo.org/wcmsp5/groups/public/---ed_norm/--declaration/documents/publication/wcms_243391.pdf

MARTÍNEZ ESCAMILLA, M. (2008). ¿Puede utilizarse el derecho penal en la lucha contra la inmigración irregular", Revista Electrónica de Ciencia Penal y Criminología - RECPC10-06, Disponible online en: http://criminet.ugr.es/recpc/10/recpc10-06.pdf 
(2009) "Inmigración, Derechos Humanos y Política Criminal: ¿hasta dónde estamos dispuestos a llegar?", InDret Penal. Revista para el Análisis del Derecho, $n^{\circ} 3$, Disponible online en:

http://www.raco.cat/index.php/InDret/article/view/138050

MARTOS NÚÑEZ, J.A. (2012): El delito de trata de seres humanos: análisis del artículo 177 bis del código penal, Estudios Penales y Criminológicos, vol. XXXII (2012)

http://www.usc.es/revistas/index.php/epc/article/view/896

MAYORDOMO RODRÍGO, V. (2007): La pertenencia a organización delictiva en el tráfico ilegal de personas, Eguzkilore. Cuaderno del Instituto Vasco de Criminología - $n^{\circ} 21$ Disponible online en: https://dialnet.unirioja.es/servlet/articulo? codigo $=3289424$

MIRÓ LLINARES, F. (2008): Política comunitaria de inmigración y política criminal en España ¿Protección o "exclusión" penal del inmigrante? Revista Electrónica de Ciencia Penal y Criminología, RECPC 10-05. Disponible online en: http://criminet.ugr.es/recpc/10/recpc10-05.pdf MUÑOZ CONDE, F. (2010): Derecho Penal. Parte Especial. Tirant Lo Blanch: Valencia.

POMARES CINTAS. E. (2011): El delito de trata de seres humanos con finalidad de explotación laboral, Revista Electrónica de Ciencia Penal y Criminología - RECPC 13- 15 Disponible online en:

http://criminet.ugr.es/recpc/13/recpc13-15.pdf

ROPERO CARRASCO, J. / RUILOBA ALVARIÑO, J. (2012). Explotación sexual y prostitución: paradojas e hipocresías que impiden la protección de las víctimas, Letras jurídicas: revista de los investigadores del Instituto de Investigaciones Jurídicas $U . \quad V ., n^{\circ} 25$, Disponible online en: https://dialnet.unirioja.es/servlet/articulo? codigo $=4486367$

SANTANA VEGA, D. $M^{a}(2011)$. La Directiva 2011/36/UE, relativa a la prevención y lucha contra la trata de seres humanos y la protección de las víctimas: análisis y crítica, Nova et Vétera, Vol. 20, $n^{\circ}$ 64, Disponible online en:

http://esapvirtual.esap.edu.co/ojs/index.php/novaetvetera/article/view 1179

VILLACAMPA ESTIARTE, C (2012). Trata de seres humanos y delincuencia organizada: Conexión entre ambos fenómenos criminales y su plasmación jurídico-penal, Indret: Revista para el Análisis del Derecho, $\mathrm{n}^{\circ}$ 1, Disponible online en: http://www.indret.com/pdf/869.pdf

WHITE, R. \& OVEY, C. (2010). The European Convention on Human Rights. $5^{\circ}$ ed. OUP: Oxford 